\title{
NOTES
}

\section{Effect of Moisture on the Aggregation of Methylene Blue and Rhodamine 6G in Poly $(N$-vinylpyrrolidone) Film}

\author{
Soichi Otsuki and Kimihiro AdachI \\ Osaka National Research Institute, AIST, 1-8-31 Midorigaoka, \\ Ikeda, Osaka 563, Japan
}

(Received September 7, 1994)

\begin{abstract}
KEY WORDS Methylene Blue / Rhodamine 6G / Dye / Aggregation / Moisture / Poly( $N$-vinylpyrrolidone) Film / Absorption Spectrum /
\end{abstract}

Some cationic dyes undergo dimer or higher aggregate formation with increasing concentration in aqueous solution. Although polymer films containing dyes are important materials for photonics, little work has been done on the aggregation of dyes in polymer film. ${ }^{1,2}$ It is predicted that the aggregation of dyes significantly affects the optical properties of the films. In addition, the aggregation of dyes is dependent on the microenvironment of the polymer, which is significantly influenced by the sorption of gases or vapors. In practical applications, however, polymer films are often employed under various conditions necessitating exposure to various gases or vapors.

In this study, the effects of moisture on the aggregation of 3,7-bis(dimethylamino)phenothiazin-5-ium chloride, methylene blue (MB) and 9-[2-(ethoxycarbonyl)phenyl]-3,6-bis(ethylamino)-2,7-dimethylxanthylium chloride, rhodamine $6 \mathrm{G}$ (R6G) were investigated for $\operatorname{poly}(N$-vinylpyrrolidone) (PVP) film. The absorption spectra of these dyes in the film were measured at various relative humidities (RH) and concentrations of dyes. The mechanism of the reversible aggregation of dye is discussed in relation to the change in the polarity of the microenvironment and the formation of water cluster in the film.

\section{EXPERIMENTAL}

\section{Film Preparation}

MB (extra pure; Ishizu), R6G (95\%; Aldrich) and PVP (MW 360000; Nacalai) were used as received. Ethanol solutions were prepared with various concentrations of dyes and $4.0 \%$ (g per $100 \mathrm{ml}$ ) of PVP. Films were prepared by casting the solutions on $30 \times$ $9.5 \mathrm{~mm}$ glass plates and allowing the solvent to evaporate. Thickness of the resulting films was about $14 \mu \mathrm{m}$, as calculated from the volume of the cast solution assuming that the density of the films equals 1.0 .

\section{Measurement of Absorption Spectrum}

Absorption spectrum was measured on a Shimadzu UV-2200 double-beam spectrometer under air streams with varying RH. A gas flow system was constructed by use of a Shin-ei SRH-1R humidity generator equipped with rotameters of the maximum flow rate of $11 \mathrm{~min}^{-1}$. Full details are given elsewhere. ${ }^{3}$ Measurements were carried out at $25.0^{\circ} \mathrm{C}$.

\section{Measurement of Water Vapor Sorption}

The samples used were films cast on a $18 \times 18 \mathrm{~mm}$ glass plate. Water vapor sorption was measured at $25.0^{\circ} \mathrm{C}$ with a Cahn 2000 electrobalance and a gas flow system. Detail 
procedures are in the preceding paper. ${ }^{3}$

\section{RESULTS AND DISCUSSION}

Figure 1 shows the absorption spectra of MB measured at three different concentrations of MB for PVP film under air streams with various RHs. For comparison, the absorption spectrum of MB in $N$-methyl-2-pyrrolidone (MP) is shown in Figure 2. It is supposed that MB exists in monomeric form in MP at such a low concentration. The spectrum at $0 \% \mathrm{RH}$ in the film has a strong peak at $668 \mathrm{~nm}$ and a slight hump around $620 \mathrm{~nm}$. The relative intensity of the hump for the film is larger than for the solution, and increases with MB concentration. The $668 \mathrm{~nm}$ band shifts a little to a longer wavelength with increasing $\mathrm{RH}$ from 0 to $32 \%$ or $51 \%$, but decreases rapidly with further increase in RH. On the other hand, the $620 \mathrm{~nm}$ band increases relatively by increasing $\mathrm{RH}$. The higher the MB concentration, the more

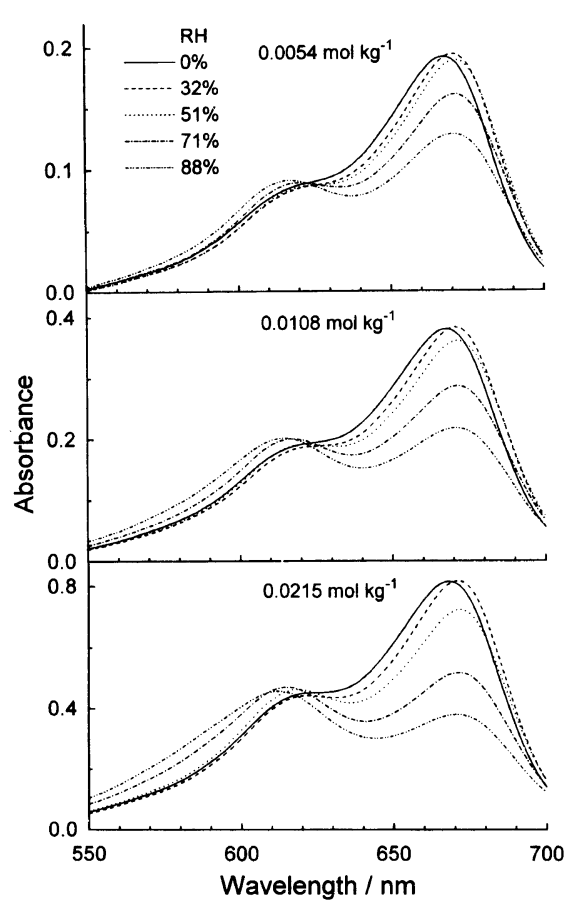

Figure 1. Absorption spectra of MB in a PVP film at various RHs. significant this behavior. Long- and shortwavelength bands have been assigned to monomeric and dimeric $\mathrm{MB}$, respectively. ${ }^{4,5}$ Thus, the aggregation of dye progresses as the dye concentration or RH increases.

Figure 3 shows the absorption spectra of R6G measured at three different concentrations of

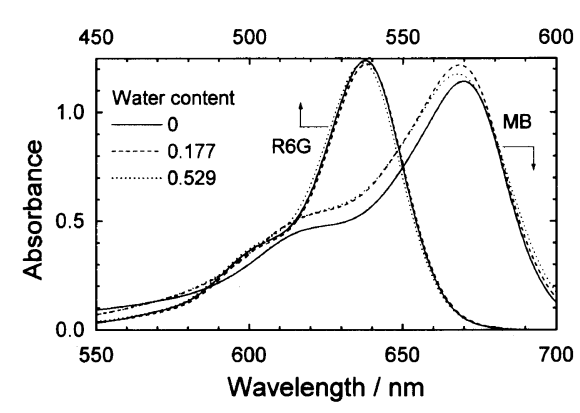

Figure 2. Absorption spectra of $M B$ and R6G in MPwater. Water content is defined here as g per $\mathrm{g}$ MP. Water content of $0,0.177$, and 0.529 corresponds to that at 0 , 51 , and $88 \% \mathrm{RH}$, respectively, in a PVP film. Concentration: MB, $1.60 \times 10^{-5} \mathrm{M}$; R6G, $1.18 \times 10^{-5} \mathrm{M}$.

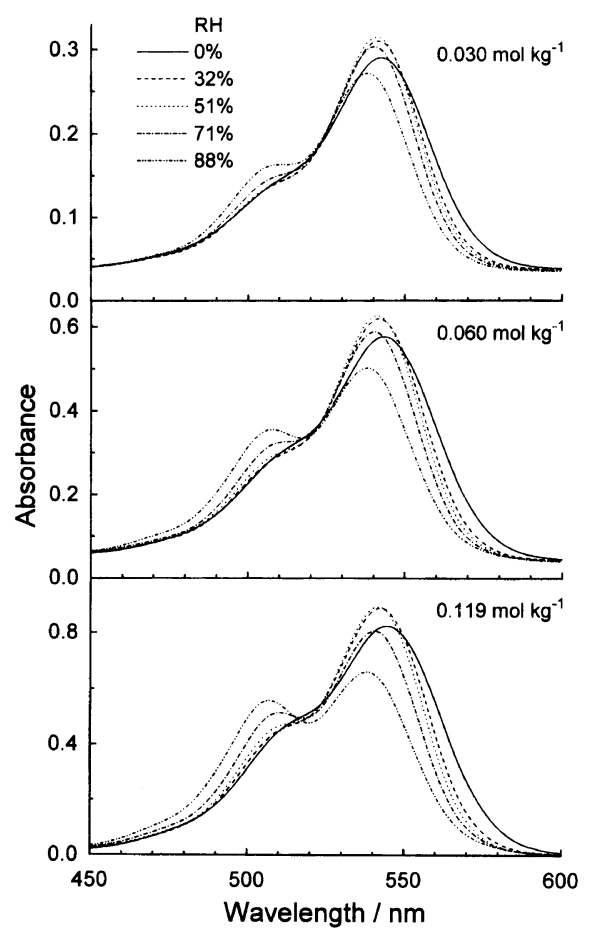

Figure 3. Absorption spectra of R6G in a PVP film at various RHs. 
R6G for PVP film under air streams with various RHs. For comparison, the absorption spectrum of R6G in MP is shown in Figure 2. It is supposed that R6G exists in monomeric form in MP at such a low concentration. The spectrum at $0 \% \mathrm{RH}$ in the film has a strong peak around $543 \mathrm{~nm}$ and a slight hump around $510 \mathrm{~nm}$. The relative intensity of the hump for the film is larger than for the solution, and increases with R6G concentration. This is attributed to aggregate formation since similar phenomena have been reported in aqueous and organic solution. ${ }^{6,7}$ The $543 \mathrm{~nm}$ band shifts to a shorter wavelength with increasing RH. This band also exhibits a small increase with $\mathrm{RH}$ from 0 to $32 \%$ or $51 \%$, but exhibits a large decrease with further increase in RH. On the other hand, the $510 \mathrm{~nm}$ band increases relatively by increasing $\mathrm{RH}$. The higher the R6G concentration, the more significant this behavior. It has been demonstrated that the most intense bands of the pure monomer and dimer are at $526 \mathrm{~nm}$ and $500 \mathrm{~nm}$, respectively, in water. ${ }^{8}$ These results indicate that the aggregation of dye progresses as the dye concentration or RH increases.

Thus, the concentration- and humiditydependent dimerization of MB and R6G occurs in the PVP film. It has been reported that the trimer as well as the dimer is formed in concentrated solutions for $\mathrm{MB}^{9}$ and $\mathrm{R} 6 \mathrm{G} .^{7,10}$ Naturally, it is expected that the dimerization is followed by the formation of higher aggregates at high concentrations and at high RHs also in PVP films.

The long-wavelength bands of MB and R6G exhibited long- and short-wavelength shifts, respectively. As can be seen in Figure 2, the long-wavelength band exhibits a short-wavelength shift for MB and little shift for R6G when water content increases in the MP-water solutions. These findings are different from the band shifts for the PVP films, which probably result from the dimerization of the dyes.

The polarity of medium can be suitably represented by $E_{\mathrm{T}}(30)$ computed from the lowest wavenumber absorption maximum of Reichardt's betaine dye. ${ }^{11}$ It has been demonstrated that $E_{\mathrm{T}}(30)$ of PVP film increases with ambient $\mathrm{RH}$, and that the increase of this value is significant at low RH but is much less at high RH. ${ }^{12}$ As shown in Figure 4, water content of PVP films with and without dyes increases slowly with RH at low RH. Therefore, it can be said that a small amount of water strongly affects the polarity of PVP.

It has been reported that the tendency of the aggregation of dyes in water-ethanol depends on the dielectric constant of solvent; ${ }^{4}$ addition of the strongly polar solvent, water, to the solution of thionine in the less polar solvent, ethanol, causes a sharp rise in the free energy of dimerization. In this study, spectral changes by aggregate formation became most prominent at high RH for both dyes. This cannot be explained only by increase in polarity, which should be more significant at low RH according to change in $E_{\mathrm{T}}(30)$. It has been demonstrated that adsorbed water forms clusters at high RHs in PVP. ${ }^{13}$ As can be seen in Figure 4, the water-vapor sorption behavior of PVP film was hardly affected by the presence of the dyes. Because the dyes are more soluble in water than in MP, it is supposed that the dye molecules gather into the water-rich phase from the

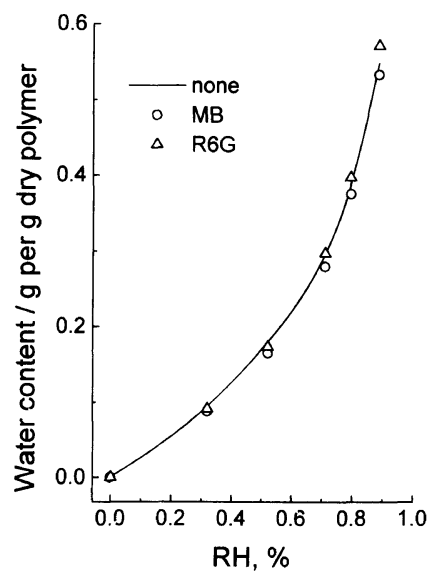

Figure 4. Isotherm of water vapor sorption for PVP films with and without dyes. Concentration: MB, 0.0215 $\mathrm{mol} \mathrm{kg}{ }^{-1}$; R6G, $0.119 \mathrm{~mol} \mathrm{~kg}^{-1}$. 


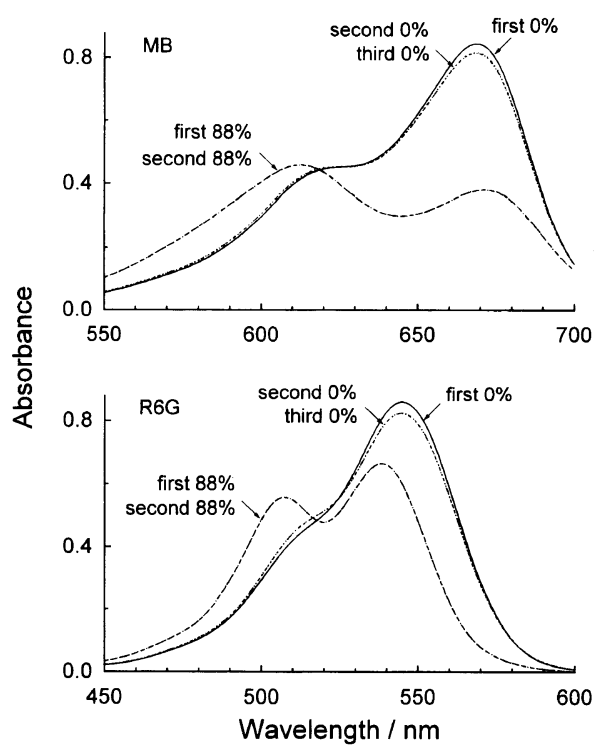

Figure 5. Absorption spectra of $\mathrm{MB}$ and R6G in PVP films at 0 and $88 \%$ RHs. Concentration: MB, 0.0215 $\mathrm{mol} \mathrm{kg}{ }^{-1}$; R6G, $0.119 \mathrm{~mol} \mathrm{~kg}^{-1}$.

PVP-rich phase. The predominant solution of dye into the water cluster may be responsible for dye aggregation in this case. It seems that the adsorption of water vapor promotes dye aggregation due to increase in polarity at low RHs and due to the formation of water clusters at high RHs.

Figure 5 reveals the reversibility of changes in the absorption spectra of the dyes. The curve of the second $0 \% \mathrm{RH}$ is identical with that of the third $0 \% \mathrm{RH}$ for both dyes. This is also the case for the curves of $88 \% \mathrm{RH}$. However, the curve of the first $0 \% \mathrm{RH}$ slightly deviates from the others measured at $0 \% \mathrm{RH}$ for both dyes. The long-wavelength band of the former is larger than that of the latter, whereas the short-wavelength band is smaller than that of the latter. This tendency became less significant as dye concentration decreased. It can be said that absorption spectra are unchanged after humidification and desiccation processes except for freshly cast films. The dye molecules may be distributed fairly homogeneously in a freshly cast film. However, they have the most stable distribution once the film adsorbs a lot of water vapor and the water clusters are formed. This may support the above explanation that the formation of water clusters is responsible for aggregate formation at high RH.

\section{REFERENCES}

1. K. Y. Law and R. O. Loutfy, Macromolecules, 14, 587 (1981).

2. S. Otsuki and K. Adachi, Polym. J., 25, 1107 (1993).

3. S. Otsuki and K. Adachi, J. Appl. Polym. Sci., 48, 1557 (1993).

4. E. Rabinowitch and L. F. Epstein, J. Am. Chem. Soc., 63, 69 (1941).

5. K. Bergmann and C. T. O'Konski, J. Phys. Chem., 67, 2169 (1963).

6. F. L. Arbeloa, I. L. Gonzalez, P. R. Ojeda, and I. L. Arbeloa, J. Chem. Soc., Faraday Trans. 2, 78, 989 (1982).

7. F. L. Arbeloa, P. R. Ojeda, and I. L. Arbeloa, J. Chem. Soc., Faraday Trans. 2, 84, 1903 (1988).

8. I. U. Aguirresacona, F. L. Arbeloa, and I. L. Arbeloa, J. Chem. Educ., 66, 866 (1989).

9. A. K. Ghosh, Z. Phys. Chem. (Frankfurt am Main), 94, 161 (1975).

10. P. R. Ojeda, I. A. K. Amashta, J. R. Ochoa, and I. L. Arbeloa, J. Chem. Soc., Faraday Trans. 2, 84, 1 (1988).

11. C. Reichardt, Angew. Chem., 91, 119 (1979).

12. R. A. McGill, M. S. Paley, and J. M. Harris, Macromolecules, 25, 3015 (1992).

13. H. H. G. Jellinek, M. D. Luh, and V. Nagarajan, Kolloid Z.-Z. Polym., 232, 758 (1969). 